\title{
Sleep - more local and complex than previously thought?
}

\author{
Lisa Genzel ${ }^{* t}$ and Martin Dresler \\ Max Planck Institute of Psychiatry, Munich, Germany \\ ${ }^{*}$ Correspondence: genzel@mpipsykl.mpg.de \\ ${ }^{+}$Current address: \\ Lisa Genzel, Centre for Cognitive and Neural Systems, University of Edinburgh, 1 George Square, EH8 9JZ Edinburgh, UK.
}

\section{A commentary on}

Hippocampal sleep features: relations to human memory function

by Ferrara, M., Moroni, F., De, G. L., and Nobili, L. (2012). Front. Neur. 3:57. doi: 10.3389/fneur.2012.00057

The review by Ferrara et al. (2012) provides a summary of a fascinating method of researching sleep, which is gaining more and more importance and momentum in the literature. Intra-cranial-EEG recordings provide us with the unique opportunity to delve more deeply into the human brain instead of just "scratching on the surface." The classical Rechtschaffen and Kales classification of sleep has been a reliable and faithful way to view sleep for more than 40 years. However, criticisms have arisen (Himanen and Hasan, 2000) and it is perhaps time to advance to a new age and not see sleep as a whole-brain state anymore. For example, during sleepwalking a dissociation of activity in different brain regions can be observed, with strongly enhanced activity in the cerebellum and cingulate cortex while large areas of frontal and parietal association cortices remain deactivated (Bassetti et al., 2000). Another example is lucid dreaming, in which prefrontal and medial parietal regions become activated during otherwise normal REM sleep (Voss et al., 2009; Dresler et al., in press). However, as Ferrara et al. nicely summarized in their review, intracranial-EEG recordings suggest that also normal sleep is a rather local phenomenon. Slow oscillations (Nir et al., 2011) as well as spindles (Andrillon et al., 2011) seem to occur more locally and not globally. Further, different brain areas, e.g., hippocampus and cortex seem to be able to display features of different sleep-states - REM and NREM - at the same time (Moroni et al., 2012).

The review also highlights the evidence regarding sleep features important for memory consolidation. They present cumulative data suggesting that perhaps during hippocampal sharp wave ripples (hSWR) a replay of the memory trace occurs, which is then "transferred" into the cortex via sleep spindles and perhaps slow oscillations. At this point it is important to note that for one most evidence regarding this theory is of correlative nature and therefore cannot conclude causality. Up until now only two studies in rodents could show more than correlational evidence by actively disrupting SWR and therefore causing decreased memory consolidation (Girardeau et al., 2009; Ego-Stengel and Wilson, 2010). A more recent study in humans showed enhanced memory performance by stimulation of the entorhinal region during memory encoding (Suthana et al., 2012). Perhaps future studies could combine these two approaches. Another important caveat is that replay coinciding with hSWR is seen in wake-rest as well as sleep (Axmacher et al., 2008). In Axmachers study the highest incidence of ripples occurred during rest and the ripples during rest actually correlated with memory performance. However, studies in rodents reported that cortical replay of memory related neural-patterns only occurred during sleep-SWR (Peyrache et al., 2010). Perhaps hippocampal replay and thus consolidation occurs during wake and sleep-SWR, but this replay can only be coordinated with cortical replay and thus cortical consolidation during sleep, which provides the required network properties. Connectivity analyses in human fMRI studies could show general decreased corticalcortical connectivity during slow wave sleep, but increased cortical-cortical connectivity during stage 2 light sleep (Spoormaker et al., 2010). And even more compelling, the same group could show increased hippocampalcortical connectivity during sleep spindles (Andrade et al., 2011). Surprisingly a very recent study in rodents presented that during sleep spindles the cortex seems to be functionally deafferented from its hippocampal inputs (Peyrache et al., 2011). Further, Dang-Vu et al. (2010) provided evidence that humans who generate more sleep spindles exhibit a higher tolerance for noise during sleep and they suggest that the function of sleep spindles is to enable consolidation by blocking interfering processes. Perhaps the increased connectivity found by Andrade et al. was due to the close temporal coupling of sleep spindles and hSWR and not because of the properties of the spindles themselves. Hopefully future studies investigated sleep via intra-cranial-EEG recordings in humans will provide a better understanding of these issues. However, we should never forget that these recordings are always made in patients with pharmacologically resistant epilepsy undergoing evaluation for surgery and not healthy subjects. To arrive at the point of needing such an evaluation the patients have suffered under sever forms of epilepsy for many years. This makes it likely that some damage to the neural circuits has occurred and perhaps compensatory mechanisms have been activated. Further, the actual cause of the epilepsy can also impact the findings.

In summary, studies investigating memory and sleep via intra-cranial-EEG recording show much promise to provide us with invaluable insights into physiological processes and will perhaps carry us into the next generation of sleep research perceiving sleep as a more complex and local instead of a global phenomenon.

\section{REFERENCES}

Andrade, K., Spoormaker, V., Dresler, M., Wehrle, R., Holsboer, F., Sämann, P.G., and Czisch, M. (2011).Sleep spindles and hippocampal functional connectivity in human NREM sleep. J. Neurosci. 31, 10331-10339.

Andrillon, T., Nir, Y., Staba, R. J., Ferrarelli, F., Cirelli, C., Tononi, G., and Fried, I. (2011). Sleep spindles in humans: insights from intracranial EEG and unit recordings. J. Neurosci. 31, 17821-17834.

Axmacher, N., Haupt, S., Fernández, G., Elger, C. E., and Fell, J. (2008). The role of sleep in declarative memory consolidation - direct evidence by intracranial EEG. Cereb. Cortex 18, 500-507. 
Bassetti, C., Vella, S., Donati, F., Wielepp, P., and Weder, B. (2000). SPECT during sleepwalking. Lancet 356, 484-485.

Dang-Vu, T. T., McKinney, S. M., Buxton, O. M., Solet, J. M., and Ellenbogen, J. M. (2010). Spontaneous brain rhythms predict sleep stability in the face of noise. Curr. Biol. 20, R626-R627.

Dresler, M., Wehrle, R., Spoormaker, V. I., Koch, S. P., Holsboer, F., Steiger, A., Obrig, H., Sämann, P. G., and Czisch, M. (in press). Neural correlates of dream lucidity obtained from contrasting lucid vs. non-lucid REM sleep: a combined EEG/fMRI case study. Sleep.

Ego-Stengel, V. R., and Wilson, M. A. (2010). Disruption of ripple-associated hippocampal activity during rest impairs spatial learning in the rat. Hippocampus 20, $1-10$.

Ferrara, M., Moroni, F., De, G. L., and Nobili, L. (2012). Hippocampal sleep features: relations to human memory function. Front. Neur. 3:57. doi: 10.3389/ fneur.2012.00057

Girardeau, G., Benchenane, K., Wiener, S. I., Buzsáki, G., and Zugaro, M. B. (2009). Selective suppression of hippocampal ripples impairs spatial memory. Nat. Neurosci. 12, 1222-1223.
Himanen, S. L., and Hasan, J. (2000). Limitations of Rechtschaffen and Kales. Sleep Med. Rev. 4, 149-167. Moroni, F., Nobili, L., De Carli, F., Massimini, M., Francione, S., Marzano, C., Proserpio, P., Cipolli, C., De Gennaro, L., and Ferrara, M. (2012). Slow EEG rhythms and inter-hemispheric synchronization across sleep and wakefulness in the human hippocampus. Neuroimage 60, 497-504.

Nir,Y., Staba, R., Andrillon, T., Vyazovskiy, V.V., Cirelli, C., Fried, I., and Tononi, G. (2011). Regional slow waves and spindles in human sleep. Neuron 70, 153-169.

Peyrache, A., Battaglia, F. P., and Destexhe, A. (2011). Inhibition recruitment in prefrontal cortex during sleep spindles and gating of hippocampal inputs. Proc. Natl. Acad. Sci. U.S.A. 108, 17207-17212.

Peyrache, A., Benchenane, K., Khamassi, M., Wiener, S. I., and Battaglia, F. P. (2010). Sequential reinstatement of neocortical activity during slow oscillations depends on cells' global activity. Front. Syst. Neurosci. 3:18. doi: 10.3389/neuro.06.018.2009

Spoormaker, V. I., Schröter, M. S., Gleiser, P. M., Andrade, K. C., Dresler, M., Wehrle, R., Sämann, P. G., and Czisch, M. (2010). Development of a large-scale functional brain network during human non-rapid eye movement sleep. J. Neurosci. 30, 11379-11387.

Suthana, N., Haneef, Z., Stern, J., Mukamel, R., Behnke, E., Knowlton, B., and Fried, I. (2012). Memory enhancement and deep-brain stimulation of the entorhinal area. N. Engl. J. Med. 366, 502-510.

Voss, U., Holzmann, R., Tuin, I., and Hobson, J.A. (2009). Lucid dreaming: a state of consciousness with features of both waking and non-lucid dreaming. Sleep 32, 1191-2200.

Received: 04 May 2012; accepted: 11 May 2012; published online: 04 June 2012.

Citation: Genzel L and Dresler M (2012) Sleep-more local and complex than previously thought? Front. Neur. 3:89. doi: 10.3389/fneur.2012.00089

This article was submitted to Frontiers in Sleep and Chronobiology, a specialty of Frontiers in Neurology. Copyright (c) 2012 Genzel and Dresler. This is an openaccess article distributed under the terms of the Creative Commons Attribution Non Commercial License, which permits non-commercial use, distribution, and reproduction in other forums, provided the original authors and source are credited. 